UDC 339.7

LBC 65.268.6

\title{
THE ROLE OF MODERN WORLD CURRENCIES IN PRIVATE SECTOR
}

\author{
Inna V. Kudryashova \\ Volgograd State University, Volgograd, Russian Federation \\ Marina V. Pleshakova \\ Kuban State University, Krasnodar, Russian Federation
}

\begin{abstract}
The authors compare the factors determining the scale of international world currencies transactions as saving means and means of payment. The change in the role of the US dollar, euro, pound sterling, Japanese Yen and Chinese Yuan in the private sector over the past few decades are also juxtaposed with the previous factors. The conclusion is made about an incomplete correlation of modern conditions determining the international demand for a common European and Chinese national currency, and the demand for the volumes of their use in the world.

On the basis of the comparative analysis of the volumes of world currencies transactions in different spheres, the authors demonstrate the top priority of the means of payment function in the process of calling forth the demand for these means on the part of non-residents using them as payment and saving means. It is proved that the main reasons of maintaining the dominant role of the US dollar as a world currency in the private sector are the leading position of the American economy concerning its contribution into the creation of the world product, support of a relatively high level of the development of the national financial market of the USA, long-term period of the American currency being world unit of account, low operation costs concerning the operations with them and also the inertia character of private actors of the world economy. It is shown that in a short-term period in case of a further growth of the economic power of the euro zone and China, provision of a complete convertibility of the Yuan and removal of the restrictions for non-residents in the Chinese financial market and also in case of maintaining a stable economic situation in the USA, the function of the world money will be carried out mainly by the American dollar.

Key words: world currency, functions of world currencies, currency market, international bonds, crossborder payments.
\end{abstract}

УДК 339.7

ББК 65.268 .6

\section{РОЛЬ СОВРЕМЕННЫХ МИРОВЫХ ВАЛЮТ В ЧАСТНОМ СЕКТОРЕ}

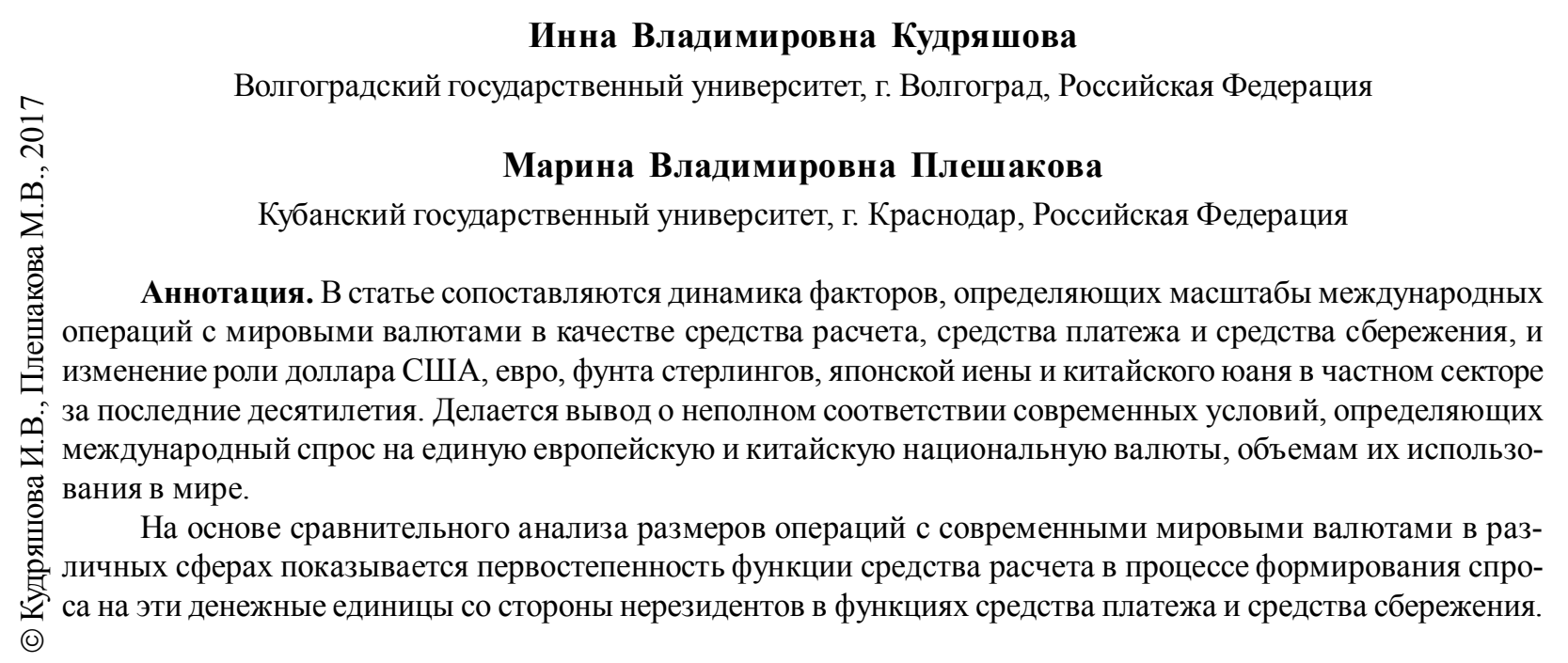


Выявлено, что основными причинами сохранения доминирующей роли доллара США как мировой валюты в частном секторе выступают лидирующие позиции американской экономики по вкладу в создание мирового продукта, поддержание относительно высокого уровня развития национального финансового рынка США, наличие продолжительной практики выполнения национальной американской валютой функций мировых денег, низкие операционные издержки по операциям с ней, а также инерционный характер поведения частных субъектов мирового хозяйства. Показано, что в краткосрочном периоде в случае дальнейшего роста экономической мощи зоны евро и Китая, обеспечения полной конвертируемости юаня и отмены ограничений для нерезидентов по операциям на китайском финансовом рынке, а также при сохранении относительно стабильной экономической ситуации в США, функции мировых денег по-прежнему будет выполнять преимущественно американский доллар.

Ключевые слова: мировая валюта, функции мировых валют, валютный рынок, международные облигации, трансграничные платежи.

Первой национальной денежной единицей, используемой за пределами страны ее эмиссии, стала афинская серебряная драхма, которая еще в V в. до н. э. применялась во внешнеторговых расчетах не только самой Греции, но еще и Азии, Индии и Северной Европы [15]. В этом и более поздних случаях возникновение и функционирование международных валют основано на необходимости субъектов частного сектора совершать расчеты по внешнеторговым операциям. Поскольку для оплаты поставок товаров изза границы импортеру требовалось приобрести валюту страны экспортера, то необходимо было найти продавца такой валюты, что было проблематичным, если экспорт осуществлялся из страны с небольшим объемом внешнеторговых операций. Использование же в подобных случаях какой-либо одной/нескольких национальных денежных единиц, относительно широко используемых в торговых операциях нерезидентами и потому выступающими в роли международных, значительно упрощало расчеты.

Рост объема межстрановых инвестиций также вызывал потребность в международных валютах. Дело в том, что для инвестирования на внутреннем рынке поступающие изза границы средства в иностранной валюте сначала необходимо было продать в обмен на национальные деньги, что требовало наличия соответствующего спроса. Реализация подобной конверсионной сделки могла быть затруднена, если ни у кого из хозяйствующих субъектов страны-импортера капитала не возникала потребность погасить финансовые обязательства или оплатить импорт товаров в этой валюте. Использование же международных валют способствовало ускорению реализации инвестиционных сделок и снижению возникающих в их процессе издержек [4].

Постепенное увеличение субъектов мирового хозяйства, рост объема операций между ними способствовали формированию мировых валют. Современные ученые и практики дают им относительно однозначное толкование - разновидность международных денежных единиц, выполняющих функции средства расчета, средства платежа и средства сбережения во всем мире. К их числу относят денежные единицы, наделенные МВФ статусом свободно используемых, и потому входящих в валютную корзину СДР $[1 ; 6 ; 15 ; 19]$. При этом МВФ определяет свободно используемую валюту как валюту, фактически широко применяемую в платежах по международным сделкам и торгуемую на основных валютных рынках в значительных масштабах. Перечень современных мировых валют МВФ определил в 1980 году. С тех пор и по настоящее время он изменялся дважды. В 1999 г. евро заменило немецкую марку и французский франк в составе корзины, состоящей в 1981-1998 гг. из пяти валют [23]. С октября 2016 г. после включения национальной денежной единицы КНР корзина СДР вновь состоит из пяти валют: доллар США, евро, фунт стерлингов, японская иена и юань [16].

Интернационализация отдельных национальных/единой валют возможна только в определенных условиях, способствующих формированию спроса на них со стороны нерезидентов, а также обеспечивающих возможность совершения различных операций в них. Тем не менее юридическое по сути достижение какой-либо валютой статуса мировой на практике не всегда проявляется активным использованием ее в мире, что может быть 


\section{ЗАРУБЕЖНЫЙ ОПЫТ НАДНАЦИОНАЛЬНОГО РЕГУЛИРОВАНИЯ}

следствием действия различных факторов, определяющих интенсивность ее международного применения в отдельной денежной функции. Проанализируем масштабы использования современных мировых валют в качества средства расчета, средства платежа и средства сбережения в частном секторе.

Мировая валюта является средством расчета в частном секторе, если применятся при выставлении счетов в межстрановой торговле, установлении цен на товары и услуги во внешнеторговых контрактах, номинировании финансовых инструментов в международных сделках, а также при определении цены рабочей силы (например, в форме почасовых ставок, которые варьируются между отдельными странами) [19].

Выбор валюты счетов в торговле сырьевыми товарами определяется в основном существующей практикой международного обмена товарами. Так, например, цена в торговле каучуком устанавливается в фунтах стерлингов, а на нефть, медь, пшеницу и пр. в долларах США.

В торговле же готовой продукцией между развитыми странами внешнеторговые счета преимущественно выставляются в валюте страны-экспортера, иногда - в валюте страны-импортера и только в отдельных случаях - в валюте третьих стран. Обмен такими же товарами между развитыми и развивающимися странами обычно оценивается в валютестраны-производителя или же в валюте какой-либо третьей страны, а между развивающимися странами в основном в валюте третьих стран [21].

Результаты современных исследований показывают, что основными факторами, определяющими выбор валюты для выставления счета по международным контрактам купли-продажи, выступают объем производ- ства страны/региона, ее эмитирующей, режим и стабильность ее курса, операционные издержки (разница между курсами покупки и продажи), а также существование международного опыта выставления счетов в этой валюте. При этом последние два фактора носят взаимно поддерживающий характер: чем ниже операционные затраты по сделкам с какой-либо валютой, тем большее использование она находит в качестве валюты выставления международных счетов, что, в свою очередь, способствует сокращению издержек, связанных с ее применением [13; 21].

США остаются крупнейшим производителем в мире (табл. 1). На их долю в 2016 г. приходилось почти 25 \% мирового выпуска. Образовавшаяся в 1999 г. зона евро выступает серьезным конкурентом США по размеру удельного веса в мировом продукте. Кроме того, за последние десятилетия существенно возросло значение этого показателя в Китае: в 2015 г. он уже находился на одном уровне с зоной евро. И хотя вклад Японии и Великобритании в создание мирового ВВП сократился, тем не менее, они находятся на 4-м и 5-м местах в мире, уступая лишь другим эмитентам мировых валют.

Активное, начиная с конца Второй мировой войны, использование доллара США в процессе международных расчетов во многом определено отсутствием валютных ограничений. Полная конвертируемость валют стран Западной Европы, позже составивших валютный союз с общей денежной единицей - евро, была достигнута к началу 1960-х годов. После отмены в конце 1970-х гг. валютных ограничений в Японии иена тоже стала свободно конвертируемой валютой [3]. К моменту официального достижения статуса мировой валюты в 2016 г. конвертируемость китайского юаня

Таблица 1

Доля эмитентов мировых валют в мировом ВВП в 1981-2016 гг., \%

\begin{tabular}{|c|c|c|c|c|c|c|c|}
\hline Год & США & Германия & Франция & Зона евро & $\begin{array}{c}\text { Велико- } \\
\text { британия }\end{array}$ & Япония & Китай \\
\hline 1981 & 25,7 & 6,4 & 4,9 & - & 4,3 & 9,7 & 2,3 \\
\hline 1991 & 25,8 & 7,7 & 5,3 & - & 4,7 & 14,8 & 1,7 \\
\hline 2001 & 32,1 & $\mathrm{x}$ & $\mathrm{x}$ & 19,8 & 4,8 & 12,9 & 4,0 \\
\hline 2011 & 21,3 & $\mathrm{x}$ & $\mathrm{x}$ & 18,6 & 3,6 & 8,4 & 10,3 \\
\hline 2016 & 24,4 & $\mathrm{x}$ & $\mathrm{x}$ & 15,5 & 3,4 & 6,4 & 14,9 \\
\hline
\end{tabular}

Примечание. Составлено авторами по: [14]. 
была ограничена по капитальным операциям, хотя меры контроля по операциям с капиталом в КНР выборочно отменяются. Значительно же повысить конвертируемость юаня власти страны планируют только к 2020 году [2].

Режим валютных курсов доллара США, евро, фунта стерлингов и японской иены является свободно плавающим, что не исключает вмешательства монетарных властей в механизм ценообразования на валютном рынке. Обладая крупнейшими в мире резервными активами, их эмитентам приходится сглаживать сильные колебания курсов национальных валют: в 2000-2002 гг. в зоне евро, в 20092012 гг. в Японии. В целом же изменчивость курсов рассматриваемых валют была относительно невысокой (рис. 1).

В отличие от доллара США, евро, фунта стерлингов и японской иены, курс китайского юаня привязан к доллару США, то есть цену китайской национальной валюты определяет не рынок, а Народный банк Китая, который устанавливает жесткие рамки возможных колебаний. С марта 2014 г. этот коридор был расширен с 1 до 2 \%. Предыдущее расширение произошло в апреле 2012 г., тогда диапазон был зафиксирован в пределах $1 \%$ вместо прежних $0,5 \%$.

Отметим, что в 2015 г. произошло крупнейшее с 1994 г. однодневное снижение курса китайского юаня на $1,9 \%$. И хотя в отношении юаня подобное изменение является значительным, в целом существующий режим валютного курса в КНР не предполагает резких изменений цены юаня относительно других валют [5].

Действие указанных факторов способствовало преобладанию в валютной структуре внешнеторговых счетов мировых валют.

В 1980 г. совокупный удельный вес счетов в долларах США, немецкой марке, французском франке, фунте стерлингов, японской йене составил более 84,5\%. И хотя к 1992 г. он несколько снизился, но все еще оставался значительным - 79,9\%. Аналогичная ситуация сохранилась в начале XXI века.

На протяжении всего анализируемого периода основная часть счетов в международной торговле выставлялась в долларах США.

В 1980 г. на его долю приходилось 56,1\% счетов, в 1992 г. $-47,8 \%$, а в 2003 г. $-73,8 \%$ (от всех счетов в мире, исключая счета стран зоны евро) [25]. В 2007 г. доллару США также принадлежали ключевые позиции как средства расчета в частном секторе: США (90\% счетов по импорту), Азия (приблизительно $80 \%$ по экспорту и 76 \% по импорту), Африка (75\% по экспорту), Канада (70 \% по экспорту) и зона евро в ее сделках с не входящими в ЕС партнерами (почти 56 \% по импорту) [20].

До введения в обращение единой европейской валюты, значительная часть счетов по внешнеторговым сделкам в мире также выставлялась в немецкой марке и французском франке (соответственно 13,6 и 6,2\% в 1980 г., 15,3 и 6,3 \% в 1992 г.). С момента по-

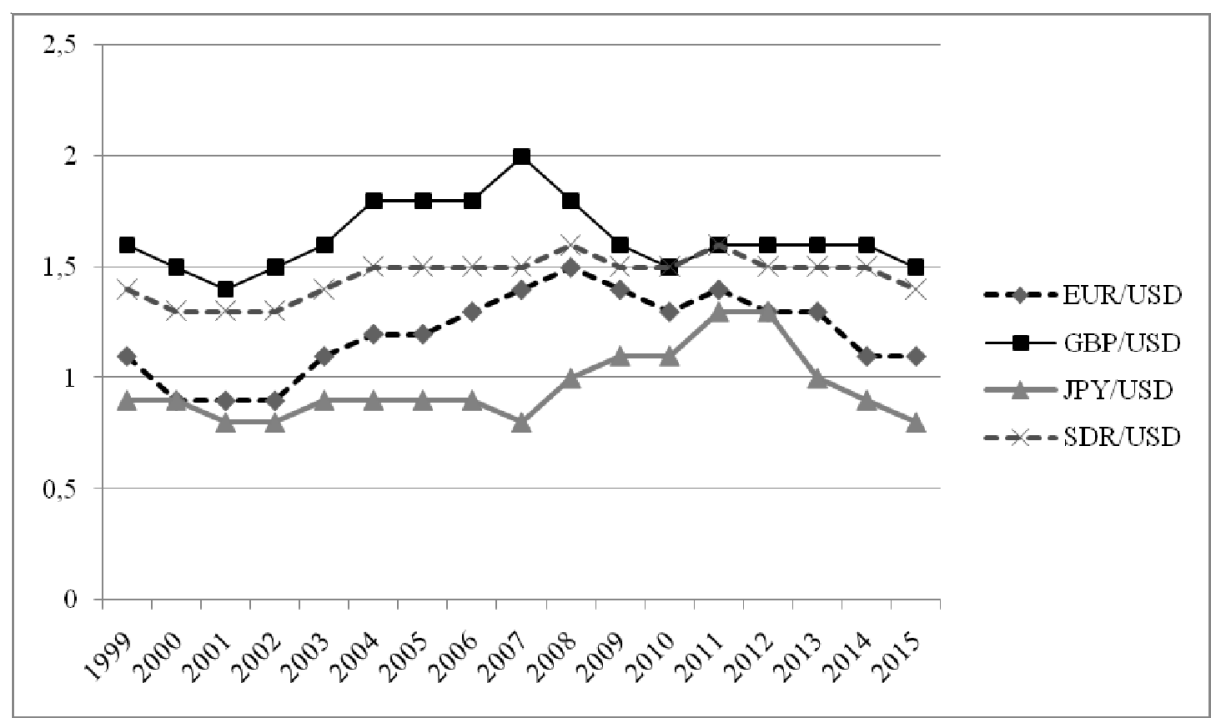

Рис. 1. Динамика курса основных мировых валют в 1999-2015 гг.

Примечание. Составлено авторами по: [8]. 


\section{ЗАРУБЕЖНЫЙ ОПЫТ НАДНАЦИОНАЛЬНОГО РЕГУЛИРОВАНИЯ}

явления роль евро как валюты счетов постепенно увеличивается. В 2003 г. на его долю приходилось 4,1 \% выставленных счетов в мире (исключая страны зоны евро). При этом в торговле ЕС оно занимало 57,3 \% (на долю доллара США приходилось 25,3 \%), а в торговле прочих европейских стран - 40,6 \% (26,1 \% в долларах США).

В 2007 г. в торговле между зоной евро и странами ЕС, не входящими в нее, приблизительно $57 \%$ счетов по экспорту и $51 \%$ по импорту было выставлены в евро. Единая европейская валюта была еще более предпочтительной во внешней торговле стран-членов $\mathrm{EC}$, не входящими в зону евро - почти $59 \%$ их экспортных счетов и 57 \% счетов импорта было номинировано в евро. Кроме того, почти $53 \%$ счетов по импортным сделкам африканских стран было выставлено в евро, что объяснимо тесными экономическими связями между бывшими колониями и их европейскими метрополиями [20].

Доступные статистические данные свидетельствуют о значительно меньшем использовании японской иены и фунта стерлингов как средства расчета в частном секторе. В 1980 г. на их долю приходилось 2,1 и 6,5\% выставленных счетов в мире. К 1992 г. доля иены несколько возросла и составила 4,8 \%, а фунта стерлингов снизилась - до 5,7 \% [23].

В целях дальнейшей интернационализации китайского юаня, начавшейся в период глобального финансового кризиса 2008-2009 гг., правительство КНР поощряет национальные компании в использовании своей отечественной валюты как средства расчетов во внешнеторговых сделках. Однако в настоящее время денежная единица КНР используется для выставления счетов пока лишь в торговле между Китаем и его торговыми партнерами. По состоянию на 2011 г. доля китайского юаня в экспортных счетах КНР была несколько меньше 10 \%. Согласно существующим прогнозам эта доля может превысить в 2018 г. 31 \% [17].

Таким образом, основной валютой, используемой в частном секторе в качестве средства расчета, остается доллар США. И хотя за анализируемый период произошло формирование зоны евро, которая обеспечивает значительный вклад в создание мирового продукта, а также увеличение доли КНР в мировом производстве до уровня зоны евро, существенного повышения доли единой европейской и китайской национальной валют в процессе выражения цен мирового рынка не произошло. Такая ситуация объясняется, прежде всего, действием внешних сетевых эффектов (network externalities), означающих инерционное поведение участников мирового рынка при выборе международной валютной единицы в краткосрочной перспективе [6].

Действительно, результаты исследований в этом направлении показывают, что даже в случае формирования всех факторов, способствующих высокому международному спросу на ту или иную валюту, фактическое изменение поведения нерезидентов и переориентация их выбора в пользу этой денежной единицы происходит лишь в долгосрочной перспективе.

Функцию средства платежа в частном секторе мировая валюта может выполнять одним из двух способов.

В одном случае импортеры используют эту валюту для оплаты поставок товаров и услуг из-за рубежа. Теоретически валюта платежа может отличаться от валюты, в которой выставлен внешнеторговый счет. Однако на практике эти две денежные единицы, как правило, совпадают [18], что подтверждается имеющимися статистическими данными о валютной структуре трансграничных платежей.

В 2012-2016 гг. доминирующая часть международных платежей - около 85 \% - совершалась в мировых валютах, из которых в 2016 г. на доллар США и евро приходилось 42,1 и 31,3 \% соответственно. Следующими по значимости валютами являются фунт стерлингов $(7,2 \%)$ и японская иена $(3,4 \%)$.

За пятилетний период произошло существенное повышение роли юаня. В январе 2012 г. он находился на 20-м месте среди валют, используемых для этой цели, а к декабрю 2016 г. значился уже на 6-й позиции (более $1,7 \%$ совокупного объема трансграничных платежей) [24].

В другом же случае мировая валюта используется как промежуточная (vehicle currency) при проведении обменных операций. Дело в том, что конвертация одной валюты в другую довольно редко производится напрямую. Обычно средства сначала обмениваются на промежуточную валюту, и только потом 
на необходимую. Использование в качестве промежуточной такой денежной единицы, транзакции с которой совершаются не только большим числом участников валютного рынка, но и в значительном объеме, позволяет существенно ускорить обмен $[19 ; 21]$.

Степень использования какой-либо валюты в качестве промежуточной определяется, прежде всего, операционными затратами, размер которых обратно пропорционально связан с объемом операций с этой денежной единицей на валютном рынке, который, в свою очередь, зависит от активности ее использования субъектами мирового рынка как средства расчета. Иными словами, активное выставление счетов в международной торговле и на международных рынках капитала в какой-либо валюте способствует снижению операционных издержек, возникающих при проведении операций с ней, что приводит к росту спроса на нее в качестве промежуточной [21].

Выбор участников международных торговых отношений в пользу мировых валют при номинировании счетов на протяжении последних десятилетий способствовал активному применению этих денежных единиц при проведении обменных операций на мировом валютном рынке.

За последние почти 30 лет значительных изменений в валютной структуре конверсионных операций в мире не произошло. Подавляющая их часть осуществляется с участием доллара США, евро, фунта стерлингов и японской иены (рис. 2).

В конце 1980-х гг. в США доллар использовался в 90 \% всех валютных сделок на мировом рынке. Его роль практически не изменилась и после введения в обращение единой европейской валюты: в 2001 г. американская национальная валюта использовалась в $90 \%$ сделок этого типа. В 2016 г. в 88 \% конверсионных валютных операций промежуточной денежной единицей выступает доллар США, $31 \%$ операций совершается в евро, $22 \%$ - в японской иене, $13 \%$ - в фунте стерлингов и $4 \%$ - в юане.

Таким образом, поскольку масштабы использования частным сектором тех или иных денежных единиц как средства платежа зависят от активности их использования в качестве средства расчета, в основном трансграничные платежи и обменные операции на мировом валютном рынке осуществляются с участием американского доллара. Значительного изменения роли других мировых валют пока не произошло.

Мировые валюты выполняют функцию средства накопления в частном секторе в том случае, если компании различных стран осуществляют свои инвестиции в форме депозитов и покупки ценных бумаг, номинированных в этих валютах [18; 19]. Масштабы использования какой-либо национальной/единой валюты в этом направлении определяются разме-

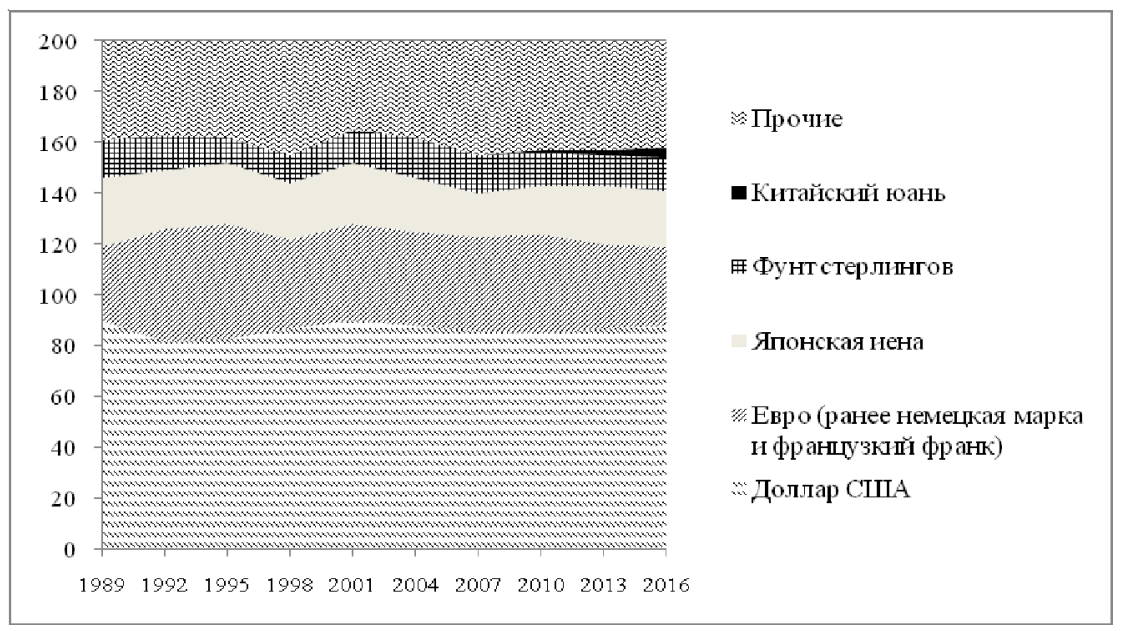

Рис. 2. Доли отдельных валют на мировом валютном рынке, \%*

Примечание. Составлено авторами по: [22; 26]. * - так как данные по операциям не детализированы в разрезе покупок и продаж валют, а приводится лишь статистика по оборотам, для их подсчета используется метод двойного счета, то есть количество сделок будет всегда в 2 раза больше. 


\section{ЗАРУБЕЖНЫЙ ОПЫТ НАДНАЦИОНАЛЬНОГО РЕГУЛИРОВАНИЯ}

ром, открытостью и ликвидность финансовых рынков страны/объединения стран, ее эмитирующей, стабильностью этой валюты [21], а также масштабами ее использования в предыдущих двух функциях [19].

В настоящее время в США, зоне евро, Великобритании и Японии функционируют открытые, свободные от жесткого государственного регулирования, высокоразвитые финансовые рынки с финансовыми центрами мирового значения в Нью-Йорке, Франкфурте-на-Майне, Лондоне и Токио, что позволяет нерезидентам эффективно размещать чистые сбережения в их национальных/единой денежных единицах. Однако за последние десятилетия произошли значительные изменения в конкурентных позициях отдельных их сегментов.

Соединенные Штаты утратили лидерство по показателям глубины финансового рынка (табл. 2). В 1981 г. лишь банковский его сегмент предлагал нерезидентам менее диверсифицированный набор активов, а также менее широкие возможности по опосредованию глобальных торговых и инвестиционных потоков в своей национальной валюте по сравнению с другими эмитентами мировых валют (за исключением Великобритании). 30 лет спустя только внутренний рынок корпоративных облигаций США предоставляет иностранным инвесторам больше способов для размещения средств по сравнению с зоной евро, Великобританией, Японией и КНР. В то же время наблюдалось значительное развитие внутреннего рынка государственных облигаций в Японии, в результате чего он стал более глубоким относительно не только США, но и зоны евро, Великобритании и Китая. Также существенно возросли отношения ежегодных значений капитализации рынка акций к ВВП в Великобритании и Японии.

Динамика финансового рынка КНР на протяжении анализируемого периода имела положительный характер, о чем свидетельствует рост показателей его глубины. Тем не менее к 2015 г. только его банковский сегмент соответствовал уровню развития финансовых рынков других эмитентов современных мировых валют. Кроме того, китайский же облигационный рынок остается для нерезидентов сравнительно закрытым. И, несмотря на неко-

Таблиияа 2

Показатели глубины финансовых рынков у эмитентов мировых валют В 1981-2015 гг., \%

\begin{tabular}{|c|c|c|c|c|c|c|c|}
\hline Год & США & Германия & Франция & Зона евро & $\begin{array}{c}\text { Велико- } \\
\text { британия }\end{array}$ & Япония & Китай \\
\hline \multicolumn{8}{|c|}{ Банковские активы / ВВП, \% } \\
\hline 1981 & 60,4 & 103,0 & 79,3 & - & 27,3 & 169,9 & $\ldots$ \\
\hline 1991 & 58,2 & 108,2 & 103,0 & - & 102,0 & 226,0 & 77,2 \\
\hline 2001 & 55,3 & $\mathrm{X}$ & $\mathrm{x}$ & 83,6 & 123,4 & 195,6 & 113,7 \\
\hline 2011 & 59,3 & $\mathrm{x}$ & $\mathrm{x}$ & 110,6 & 179,9 & 189,9 & 128,8 \\
\hline 2015 & 60,2 & $\mathrm{x}$ & $\mathrm{x}$ & $102,7 *$ & 134,7 & 165,5 & 153,4 \\
\hline \multicolumn{8}{|c|}{ Капитализация рынка акций / ВВП, \% } \\
\hline 1981 & 41,4 & 7,5 & 6,6 & - & 20,4 & 18,5 & $\ldots$ \\
\hline 1991 & 58,8 & 19,4 & 25,9 & - & 80,9 & 38,3 & $\ldots$ \\
\hline 2001 & 138,3 & $\mathrm{x}$ & $\mathrm{x}$ & 59,1 & 149,8 & 46,9 & 41,6 \\
\hline 2011 & 107,4 & $\mathrm{X}$ & $\mathrm{x}$ & 30,4 & 118,7 & 76,4 & 52,2 \\
\hline 2015 & 143,3 & $\mathrm{x}$ & $\mathrm{x}$ & $65,2 *$ & $112,1 * *$ & 99,8 & 64,1 \\
\hline \multicolumn{8}{|c|}{ Объем рынка внутренних корпоративных облигаций / ВВП, \% } \\
\hline 1991 & 70,4 & $\ldots$ & 58,0 & - & 13,7 & 40,9 & 2,9 \\
\hline 2001 & 98,8 & $\mathrm{x}$ & $\mathrm{x}$ & 24,6 & 17,3 & 53,8 & 7,9 \\
\hline 2011 & 91,9 & $\mathrm{x}$ & $\mathrm{x}$ & 37,8 & 12,3 & 72,5 & 29,5 \\
\hline 2015 & $\ldots$ & $\mathrm{x}$ & $\mathrm{x}$ & $\ldots$ & $\ldots$ & 62,8 & 46,6 \\
\hline \multicolumn{8}{|c|}{ Объем рынка внутренних государственных облигаций / ВВП, \% } \\
\hline 1991 & 55,9 & $\ldots$ & 24,1 & - & 24,4 & 44,6 & 2,3 \\
\hline 2001 & 41,1 & $\mathrm{x}$ & $\mathrm{x}$ & 34,9 & 27,8 & 95,3 & 9,9 \\
\hline 2011 & 82,6 & $\mathrm{x}$ & $\mathrm{x}$ & 46,6 & 58,6 & 190,8 & 15,6 \\
\hline 2015 & $\ldots$ & $\mathrm{x}$ & $\mathrm{x}$ & $\ldots$ & $\ldots$ & 202,5 & 21,6 \\
\hline
\end{tabular}

Примечание. Составлено авторами по: [10; 12]. * - данные за 2014 год; **-данные за 2012 год. 
торые меры, обеспечивающие допуск на него нерезидентов, внутренний долговой рынок КНР по-прежнему предлагает иностранным инвесторам относительно небольшие возможности для размещения средств [2].

Охарактеризованные изменения соответствующим образом повлияли на масштабы использования долларов США, евро, фунтов стерлингов и японских иен в качестве средства сбережения в частном секторе.

Совокупная доля доллара США, евро (до 1999 г. немецкой марки и французского франка), японской иены и фунта стерлингов в валютной структуре находящихся в обращении международных облигаций имела устойчивую тенденцию роста, в результате чего в 2015 г. она превысила $93 \%$, увеличившись по сравнению с 1981 г. почти на 40 п.п. (табл. 3). При этом почти на 10 п.п. (до 42,7 \%) сократилась часть инвестиций в долговые ценные бумаги, номинированные в долларах США. Доля же международных облигаций, выраженных в единой европейской валюте, превысила не только совокупную долю денежных единиц, которые она заменила, но и в отдельные годы долю американской национальной валюты - в 2006 и 2011 гг. на 8,9 и 1,5 \% соответственно.

В валютной структуре депозитов, размещенных в иностранных банках, доля амери- канской национальной валюты тоже заметно снизилась, а доля единой европейской - хоть и не достигла уровня доллара США, но превысила суммарную долю немецкой марки и французского франка.

Таким образом, за последние десятилетия в факторах, определяющих роль современных мировых валют в частном секторе, произошли изменения, которые могли бы вызвать относительно значимую динамику в масштабах использования доллара США, евро, фунта стерлингов, японской иены и юаня в качества средства расчета, средства платежа и средства сбережения. Однако частные субъекты мирового хозяйства продолжают использовать как мировую валюту в основном американский доллар. Лишь при выполнении функции средства сбережения объем международного спроса на него снизился, а на евро - наоборот, возрос, при сохранении доминирующих позиций национальной американской валюты. Объяснением сложившейся ситуации могут быть следующие обстоятельства. Прежде всего, хотя в анализируемом периоде произошло формирование зоны евро, выпуск которой достиг значительной величины, финансовый рынок является относительно глубоким, а единая валюта - сравнительно стабильной, тем не менее, ни по одному из

Таблица 3

Валютная структура частного финансового портфеля в мире в 1981-2015 гг., \%

\begin{tabular}{|c|c|c|c|c|c|c|c|c|c|}
\hline Год & $\begin{array}{c}\text { Доллар } \\
\text { США }\end{array}$ & $\begin{array}{c}\text { Немецкая } \\
\text { марка }\end{array}$ & $\begin{array}{c}\text { Француз- } \\
\text { ский франк }\end{array}$ & Евро & $\begin{array}{c}\text { Японская } \\
\text { иена }\end{array}$ & $\begin{array}{c}\text { Фунт стер- } \\
\text { лингов }\end{array}$ & Прочие & Итого \\
\hline \multicolumn{7}{|c|}{ Валютная структура обращающихся международных облигаций } \\
\hline 1981 & 52,6 & $\ldots$ & $\ldots$ & - & 6,9 & $\ldots$ & 40,5 & 100,0 \\
\hline 1985 & 56,7 & 9,1 & 0,6 & - & 7,6 & 3,4 & 22,6 & 100,0 \\
\hline 1991 & 39,1 & 9,6 & 2,8 & - & 12,2 & 8,3 & 28,0 & 100,0 \\
\hline 1996 & 37,7 & 12,0 & 6,1 & & 14,0 & 8,3 & 22,0 & 100,0 \\
\hline 2001 & 50,7 & - & - & 31,7 & 6,0 & 7,4 & 4,2 & 100,0 \\
\hline 2006 & 36,4 & - & - & 47,3 & 2,8 & 8,2 & 5,2 & 100,0 \\
\hline 2011 & 40,7 & - & - & 42,2 & 2,7 & 7,4 & 7,0 & 100,0 \\
\hline $2015 *$ & 42,7 & - & - & 39,2 & 1,9 & 9,6 & 6,6 & 100,0 \\
\hline \multicolumn{7}{|c|}{} & \multicolumn{7}{|c|}{ Валютная структура депозитов небанковского сектора в иностранных банках } & \\
\hline 1981 & 68,9 & $\ldots$ & $\ldots$ & - & $\ldots$ & $\ldots$ & 31,1 & 100,0 \\
\hline 1985 & 69,2 & 9,3 & 1,4 & - & 3,8 & 0,9 & 15,4 & 100,0 \\
\hline 1991 & 57,8 & 14,2 & 2,5 & - & 4,0 & 1,4 & 20,1 & 100,0 \\
\hline 1996 & 46,5 & 16,2 & 1,2 & - & 3,3 & 5,8 & 27,0 & 100,0 \\
\hline 2001 & 45,1 & - & - & 25,4 & 3,3 & 6,0 & 20,2 & 100,0 \\
\hline 2006 & 47,8 & - & - & 27,6 & 2,8 & 9,0 & 12,8 & 100,0 \\
\hline 2011 & 50,0 & - & - & 27,1 & 2,8 & 6,3 & 13,8 & 100,0 \\
\hline $2015 * *$ & 50,6 & - & - & 24,2 & 2,6 & 5,7 & 16,9 & 100,0 \\
\hline
\end{tabular}

Примечание. Составлено по: [7; 22; 25]. *-данные за 2-й квартал; ** -данные за 1-й квартал. 


\section{ЗАРУБЕЖНЫЙ ОПЫТ НАДНАЦИОНАЛЬНОГО РЕГУЛИРОВАНИЯ}

этих направлений она не стала абсолютным лидером в мире. Аналогичная ситуация характерна и для Китая, в котором, кроме того, еще и сохраняются ограничения на использование национальной валюты по капитальным операциям платежного баланса, а финансовый рынок все еще относительно закрыт для иностранцев. Более того, выполняемые мировыми валютами денежные функции взаимосвязаны. Поэтому преимущественное выставление счетов по внешнеторговым сделкам в частном секторе в долларах США способствует формированию высокого спроса на него в качестве валюты платежей по международным контрактам купли-продажи, промежуточной валюты, а также при выборе валюты для осуществления инвестиций. Немаловажным обстоятельством являются и более низкие операционные издержки по операциям в долларах США, история которых более продолжительна в сравнении с единой европейской валютой и юанем. И, наконец, поведение частных субъектов мирового хозяйства при выборе международной денежной единицы в краткосрочном периоде является инерционным. В случае утраты эмитентом доминирующей валюты лидирующих позиций в мировой экономике, переориентация спроса нерезидентов в пользу другой происходит, как правило, в долгосрочной перспективе.

В связи с этим, при отсутствии глубокого кризиса в экономике США, дальнейшем росте экономической мощи зоны евро и Китая, а также обеспечении полной конвертируемости юаня и отмене ограничений для нерезидентов по операциям на китайском финансовом рынке, американский доллар в краткосрочной перспективе будет доминировать при выполнении функций мировых валют.

\section{СПИСОК ЛИТЕРАТУРЫ}

1. Красавина, Л. Н. Российский рубль как мировая валюта: стратегический вызов инновационного развития России / Л. Н. Красавина // Деньги и кредит. - 2008. - № 5. - С. 11-18.

2. Китай пообещал увеличить конвертируемость юаня к 2020 году. - Электрон. текстовые дан. Режим доступа: http://www.interfax.ru/business/ 477181. - Загл. с экрана.
3. Кудряшова, И. В. Роль организационных и институциональных условий в процессе формирования современных мировых валют / И. В. Кудряшова // Финансы и кредит. - 2015. - № 40. C. $44-50$.

4. Наркевич, С. С. Резервные валюты: факторы становления и роль в мировой экономике / С. С. Наркевич, П. В. Трунин. - М. : Изд-во Ин-та Гайдара, 2012. $-136 \mathrm{c}$.

5. ЦБ Китая расширил валютный коридор. Электрон. текстовые дан. - Режим доступа: http:// www.rosbalt.ru/business/2014/03/15/1244478. html. Загл. с экрана.

6. Chinn, M. Will the Euro Eventually Surpass the Dollar as Leading International Reserve Currency? / M. Chinn, J. Frankel// NBER Working Paper. - 2005. № 11510. - Electronic text data. - Mode of access: http://www.nber.org/papers/w11510. - DOI: 10.3386/ w11510. - Title from screen.

7. Detailed tables on BIS international banking statistics at end - March 2015 / Bank for International Settlements. - July 2015. - Electronic text data. - Mode of access: http://www.bis.org/statistics/rppb1507_ detailed.pdf. - Title from screen.

8. Dwyer, G. P. The Economics of International Monies / G. P. Dwyer, J. R. Lothian // Federal Reserve Bank of Atlanta. Working Paper. - 2003. - № 37. Electronic text data. - Mode of access: https://www. frbatlanta.org/research/publications/wp/2003/37.aspx. Title from screen.

9. Exchange rates / Organisation for Economic Cooperation and Development. - Electronic text data. Mode of access: http://stats.oecd.org/index.aspx? queryid=169\#. - Title from screen.

10. Financial Development and Structure Dataset / World Bank. - 2017. - June. - Electronic text data. Mode of access: http://www.worldbank.org/en/ publication/gfdr/data/financial-structure-database. Title from screen.

11. Foreign exchange turnover, by currency, 1995-2016 / Bank for International Settlements. Electronic text data. - Mode of access: http://www. bis.org/statistics/d11 3.pdf. - Title from screen.

12. FREDEconomic Data / Federal Reserve Bank of St. Louis. - Electronic text data. - Mode of access: https://fred.stlouisfed.org/. - Title from screen.

13. Goldberg, L. Observations on Currency Invoicing of International Trade / L. Goldberg. - 2008. - Electronic text data. - Mode of access: https://www.newyorkfed.org/ medialibrary/media/research/economists/goldberg/ PetersonIIEdollarandtradeGoldberg.pdf. - Title from screen.

14. Gross domestic product / UnctadStat. Electronic text data. - Mode of access: http:// unctadstat.unctad.org/wds/TableViewer/dimView. aspx. - Title from screen. 
15. Hartmann, P. Currency Competition and Foreign Exchange Markets: The Dollar, the Yen and the Euro / P. Hartmann. - Cambridge : Cambridge Univ. Press, 1998. $-196 \mathrm{p}$.

16. IMF's Executive Board Completes Review of SDR Basket, Includes Chinese Renminbi / International Monetary Fund. - Electronic text data. - Mode of access: https://www.imf.org/external/np/exr/faq/ sdrfaq.htm. - Title from screen.

17. Ito, H. The Rise of the "Redback" and China's Capital Account Liberalization: An Empirical Analysis on the Determinants of Invoicing Currencies / H. Ito, M. D. Chinn // ADBI Working Paper. - 2014. - № 473. Electronic text data. - Mode of access: https://thinkasia.org/bitstream/handle/11540/1235/2014.04.07. wp473.redback.prc.account.liberalization.pdf? sequence $=1 .-$ Title from screen.

18. Ito, $\mathrm{T}$. The internationalization of the RMB: opportunities and pitfalls: Paper presented to a Council on Foreign Relations / T. Ito // China Development Research Foundation symposium, The future of the international monetary system and the role of the renminbi, Beijing, 1 November, 2011. - Electronic text data. - Mode of access: https://www.cfr.org/report/ internationalization-rmb. - Title from screen.

19. Kenen, P. B. The Role of the Dollar as an International Currency / P. B. Kenen. - New York : Group of Thirty, 1983. - 40 p.

20. Nakonieczna-Kisiel, H. US Dollar and Euro as global Currencies / H. Nakonieczna-Kisiel // Folia Oeconomica Stetinensia. - 2009. - Vol. 8, iss. 1. P. 154-167. - Electronic text data. - Mode of access: https://www.degruyter.com/downloadpdf/j/foli. 2009.8.issue-1/v10031-009-0018-2/v10031-009-0018-2. pdf. - Title from screen.

21. Pollard, P. S. The Creation of the Euro and the Role of the Dollar in International Markets / P. S. Pollard // Federal Reserve Bank of St. Louis Review. - 2001. Vol. 83, № 5. - Electronic text data. - Mode of access: http://research.stlouisfed.org/publications/review/01/ 09/0109pp.pdf. - Title from screen.

22. Quarterly Review / Bank for International Settlements. - May 1997, June 2002, June 2007, June 2012, September 2015. - Electronic text data. - Mode of access: https://www.bis.org/publ/qtrpdf/r_qt1706. $\mathrm{htm} ? \mathrm{~m}=5 \% 7 \mathrm{C} 25$. - Title from screen.

23. Review of the Method of the Valuation of the SDR Initial Considerations / International Monetary Fund. - 2005. October 28. - Electronic text data. Mode of access: https://www.imf.org/external/np/pp/ eng/2005/102805.pdf. - Title from screen.

24. SWIFT RMB Monthly Tracker / Society for Worldwide Interbank Financial Telecommunications. 2012. - November. - 2017. - January. - Electronic text data. - Mode of access: https://www.swift.com/oursolutions/compliance-and-shared-services/business- intelligence/renminbi/rmb-tracker/documentcentre\#topic-tabs-menu. - Title from screen.

25. The International Use of Main Currencies. Statistical Overview of Recent Developments / by P. J. A. van de Koolwijk ; European Economic Commission. - 1994. - Electronic text data. - Mode of access: http://aei.pitt.edu/41563/1/A5661.pdf. - Title from screen.

26. Triennial Central Bank Survey of Foreign Exchange and Derivatives Market Activity 1995 - Final results / Bank for International Settlements. - Electronic text data. - Mode of access: http://www.bis.org/publ/ r_fx96.pdf. - Title from screen.

\section{REFERENCES}

1. Krasavina L.N. Rossiyskiy rubl kak mirovaya valyuta: strategicheskiy vyzov innovatsionnogo razvitiya Rossii [The Russian Rouble as the World Currency: a Strategic Challenge]. Dengi i kredit, 2008, no. 5, pp. 11-18.

2. Kitay poobeshchal uvelichit konvertiruemost yuanya $k 2020$ godu [China Has Promised to Increase the Convertibility of the Yuan by 2020]. URL: http://www.interfax.ru/business/477181.

3. Kudryashova I.V. Rol organizatsionnykh i institutsionalnykh usloviy v protsesse formirovaniya sovremennykh mirovykh valyut [The Role of Organizational and Institutional Conditions in the Modern World Currencies Formation]. Finansy $i$ kredit, 2015, no. 40, pp. 44-50.

4. Narkevich S.S., Trunin P.V. Rezervnye valyuty: faktory stanovleniya $i$ rol $v$ mirovoy ekonomike [Reserve Currencies: Factors of Evolution and their Role in the World Economy]. Moscow, Izdvo In-ta Gaydara, 2012. 136 p.

5. TsB Kitaya rasshiril valyutnyy koridor [Central Bank of China Widened the Currency Band]. URL: http:/ /www.rosbalt.ru/business/2014/03/15/1244478.html.

6. Chinn M., Frankel J. Will the Euro Eventually Surpass the Dollar as Leading International Reserve Currency? NBER Working Paper, 2005, no. 11510. URL: http://www.nber.org/papers/w11510. doi: 10.3386/w11510.

7. Detailed tables on BIS international banking statistics at end - March 2015. Bank for International Settlements. July 2015. URL: http:// www.bis.org/statistics/rppb1507_detailed.pdf.

8. Dwyer G.P., Lothian J.R. The Economics of International Monies. Federal Reserve Bank of Atlanta. Working Paper, 2003, no. 37. URL: https://www. frbatlanta.org/research/publications/wp/2003/37.aspx.

9. Exchange rates / Organisation for Economic Cooperation and Development. URL: http://stats. oecd.org/index.aspx? queryid=169\#.

10. Financial Development and Structure Dataset. World Bank, June 2017. URL: http://www. 


\section{ЗАРУБЕЖНЫЙ ОПЫТ НАДНАЦИОНАЛЬНОГО РЕГУЛИРОВАНИЯ}

worldbank.org/en/publication/gfdr/data/financialstructure-database.

11. Foreign exchange turnover, by currency, 1995-2016. Bank for International Settlements. URL: http://www.bis.org/statistics/d11_3.pdf.

12. FRED Economic Data. Federal Reserve Bank of St. Louis. URL: https://fred.stlouisfed.org/.

13. Goldberg L. Observations on Currency Invoicing of International Trade, 2008. URL: https:// www.newyorkfed.org/medialibrary/media/research/ economists/goldberg/PetersonIIEdollarandtrade Goldberg.pdf.

14. Gross domestic product. UnctadStat. URL: http:/ /unctadstat.unctad.org/wds/TableViewer/dimView.aspx.

15. Hartmann P. Currency Competition and Foreign Exchange Markets: The Dollar, the Yen and the Euro. Cambridge, Cambridge Univ. Press, 1998. 196 p.

16. IMF's Executive Board Completes Review of SDR Basket, Includes Chinese Renminbi. International Monetary Fund. URL: https://www.imf.org/external/ np/exr/faq/sdrfaq.htm.

17. Ito H., Chinn M.D. The Rise of the "Redback" and China's Capital Account Liberalization: An Empirical Analysis on the Determinants of Invoicing Currencies. ADBI Working Paper, 2014, no. 473. URL: https:/think-asia.org/bitstream/handle/11540/1235/ 2014.04.07.wp473.redback.prc.account.liberalization. pdf? sequence $=1$.

18. Ito T. The internationalization of the RMB: opportunities and pitfalls: Paper presented to a Council on Foreign Relations. China Development Research Foundation symposium, The future of the international monetary system and the role of the renminbi, Beijing, 1 November, 2011. URL: https:// www.cfr.org/report/internationalization-rmb.
19. Kenen P.B. The Role of the Dollar as an International Currency. New York, Group of Thirty, $1983.40 \mathrm{p}$.

20. Nakonieczna-Kisiel H. US Dollar and Euro as global Currencies. Folia Oeconomica Stetinensia, 2009, vol. 8, iss. 1, pp. 154-167. URL: https://www. degruyter.com/downloadpdf/j/foli.2009.8.issue-1/ v10031-009-0018-2/v10031-009-0018-2.pdf.

21. Pollard P.S. The Creation of the Euro and the Role of the Dollar in International Markets. Federal Reserve Bank of St. Louis Review, 2001, vol. 83, no. 5. URL: http://research.stlouisfed.org/publications/ review/01/09/0109pp.pdf.

22. Quarterly Review. Bank for International Settlements, May 1997, June 2002, June 2007, June 2012, September 2015. URL: https://www.bis.org/publ/ qtrpdf/r_qt1706.htm?m=5\%7C25.

23. Review of the Method of the Valuation of the SDR Initial Considerations. International Monetary Fund, 2005, October 28. URL: https://www.imf.org/ external/np/pp/eng/2005/102805.pdf.

24. SWIFT RMB Monthly Tracker. Society for Worldwide Interbank Financial Telecommunications, 2012, November - January 2017. URL: https:// www.swift.com/our-solutions/compliance-and-sharedservices/business-intelligence/renminbi/rmb-tracker/ document-centre\#topic-tabs-menu.

25. Van de Koolwijk P.J.A. The International Use of Main Currencies. Statistical Overview of Recent Developments. European Economic Commission, 1994. URL: http://aei.pitt.edu/41563/1/A5661.pdf.

26. Triennial Central Bank Survey of Foreign Exchange and Derivatives Market Activity 1995 Final results. Bank for International Settlements. URL: http://www.bis.org/publ/r_fx96.pdf.

\section{Information about the Authors}

Inna V. Kudryashova, Candidate of Sciences (Economics), Associate Professor, Department of Economic Theory, World and Regional Economy, Volgograd State University, Prosp. Universitetsky, 100, 400062 Volgograd, Russian Federation, KudryashovaIV@volsu.ru.

Marina V. Pleshakova, Candidate of Sciences (Economics), Associate Professor, Department of World Economy and Management, Kuban State University, Stavropolskaya St., 149, 350040 Krasnodar, Russian Federation, pmv23@list.ru.

\section{Информация об авторах}

Инна Владимировна Кудряшова, кандидат экономических наук, доцент кафедры экономической теории, мировой и региональной экономики, Волгоградский государственный университет, просп. Университетский, 100, 400062 г. Волгоград, Российская Федерация, KudryashovaIV@volsu.ru.

Марина Владимировна Плешакова, кандидат экономических наук, доцент кафедры мировой экономики и менеджмента, Кубанский государственный университет, ул. Ставропольская, 149, 350040 г. Краснодар, Российская Федерация, pmv23@list.ru. 